\title{
Analysis on the Preference Scale of Inbound Tourism Market in Fujian YU Tong
}

\author{
He Yuan Polytechnic, He Yuan, Guangdong, China \\ 86282557@qq.com
}

Key words: Fujian province, inbound tourism market,preference scale

\begin{abstract}
Based on the data of inbound tourism in Fujian from 2006 to 2015, we analyze the preference scale of the inbound tourist market in Fujian. The research results show that the most important inbound tourist market in Fujian is the United States, Singapore and Malaysia, the difference of the preference scale is not large, and the trend of most countries is stable. According to the results of empirical analysis, it is proposed to take measures to consolidate the Southeast Asian market as well as the European market.
\end{abstract}

\section{Introduction}

Fujian province is located in the southeast coast of China, located in the west coast of Taiwan Strait, which has rich tourism resources, including Mount Wuyi, Fujian Tulou, Gulangyu Islet , they are the famous tourism brand in Fujian of China in addition, Fujian is famous hometown of China, therefore, it attracts a large number of overseas tourists to come to Fujian for tourism. In 2006, the number of inbound foreign tourists in Fujian province is 791 thousand times.In 2015it is up to214 thousand times. During 10 years, it increases by $107.8 \%$ with a rapid development. In order to further develop the inbound tourism market in Fujian, we will take the travel time of 12 major tourist source countries from 2006 to 2015 in Fujian as the research object.Using the preference scale model, to research the development and changes principleof inbound tourism market in Fujian, we will put forward some policy suggestions.

\section{Research methods and data sources}

the preference scale model is first proposed by the Chinese scholars Ma Yaofeng and Li Tianshun, and it is an analysis method of tourist source market, which is to study the degree of tourists' preference for tourist destination [1]. The mathematical formula is expressed as:

$$
\mathrm{Q}=\frac{\mathrm{D} i / \mathrm{D} 1}{\mathrm{G} i /{ }_{\mathrm{G} 1}}
$$

Q said preference scale, Di said the visitor who visit one destination number of country which the tourists is from, $\mathrm{D}_{\mathbf{1}}$ said the visitor who visit one destination number of foreigner, $\mathrm{G} i$ said the visitor who visit China number of country which the tourists is from, $\mathrm{G}_{\mathbf{1}}$ said the visitor who visit China number of foreigner.

According to the numerical value of the degree of the preference scale, the inbound tourist market can be divided into three types (see Table 1). 
Table 1 the classificationof the preference scale of the tourist market

\begin{tabular}{|l|l|}
\hline $\begin{array}{l}\text { market which the tourists is from is of high } \\
\text { preference scale }(\mathrm{Q} \geq 1)\end{array}$ & $\begin{array}{l}\text { market which the tourists is from is of highest } \\
\text { preference } \mathrm{scale}(\mathrm{Q} \geq 2)\end{array}$ \\
\cline { 2 - 2 } & $\begin{array}{l}\text { market which the tourists is from is of higher } \\
\text { preference } \mathrm{scale}(1 \leq \mathrm{Q}<2)\end{array}$ \\
\hline $\begin{array}{l}\text { market which the tourists is from is of low } \\
\text { preference scale }(\mathrm{Q}<1)\end{array}$ & $\begin{array}{l}\text { market which the tourists is from is of lower } \\
\text { preference scale }(0.5 \leq \mathrm{Q}<1)\end{array}$ \\
\cline { 2 - 2 } & $\begin{array}{l}\text { market which the tourists is from is of lowest } \\
\text { preference scale }(0 \leq \mathrm{Q}<0.5)\end{array}$ \\
\hline $\begin{array}{l}\text { undeveloped market which the tourists is } \\
\text { from }(\mathrm{Q}=0)\end{array}$ & \\
\hline
\end{tabular}

This paper selects Japan, Philippines, Singapore, Thailand, Indonesia, Malaysia, United States, Canada, Britain, France, Germany and Australia-the 12 main source of inbound tourism in Fujian as the research object. Data from the national tourist arrivals in this paper are from the official website of the China National Tourism Administration, the data of Fujian inbound tourists is from The Fujian Statistical Yearbook (2007-2016).

\section{Empirical analysis}

According to the preference formula, we get the preference scale value of inbound tourism of the 12 main source countriesof Fujian, using Excel software to draw the figure of interannual variation (Figure 1), the use of one year's preference scale value can not reflect the numerical classification of inbound tourism market in Fujian, so we will take nearly 10 years'average value to summarize that in Table 2, with figure 1 and table 2, we will analyze the preference scale of inbound tourist marketof Fujian from 2006 to 2015.

Table 2The classification of the averagepreference scale of inbound tourist market in Fujian from 2006 to 2015

\begin{tabular}{|l|l|}
\hline \multicolumn{1}{|c|}{ Type } & \multicolumn{1}{|c|}{ Countries } \\
\hline $\begin{array}{l}\text { market which the tourists is from is of } \\
\text { highest preference scale }\end{array}$ & United States (2.88), Singapore (2.69), Malaysia (2.40) \\
\hline $\begin{array}{l}\text { market which the tourists is from is of } \\
\text { higher preference scale }\end{array}$ & $\begin{array}{l}\text { Indonesia (1.48), Japan (1.2), Canada (1.15), Germany } \\
(1.05)\end{array}$ \\
\hline $\begin{array}{l}\text { market which the tourists is from is of } \\
\text { lower preference scale }\end{array}$ & $\begin{array}{l}\text { Philippines (0.99), UK (0.98), France (0.81), Australia } \\
(0.76), \text { Thailand (0.75) }\end{array}$ \\
\hline $\begin{array}{l}\text { market which the tourists is from is of } \\
\text { lowest preference scale }\end{array}$ & There is no \\
\hline
\end{tabular}

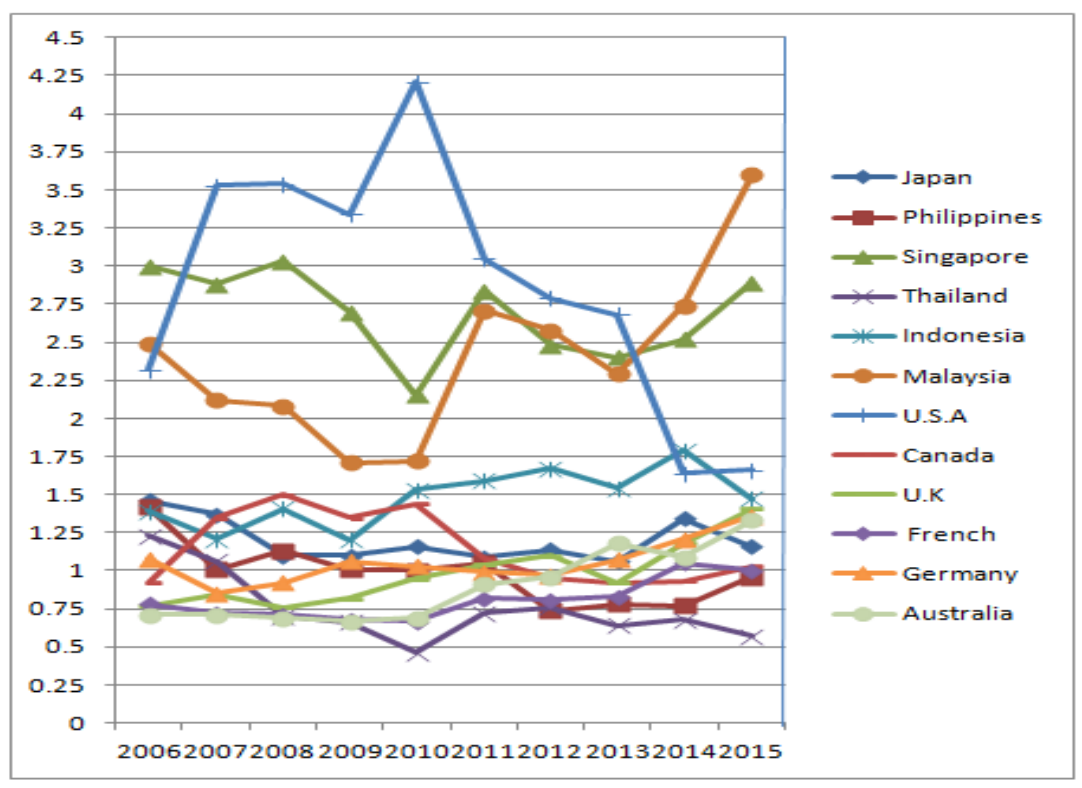

Figure 1 The annual change chart of the preference scale of inbound tourism source country in Fujian from 2006 to 2015 


\section{The comprehensive analysis of the preference scale.}

Since 2006, the preference scale value of inbound tourists of Fujian is generally high, it has7 preference markets with the proportion 58.3\%. Among them, the strong preference market includes the United States, Singapore and Malaysia, which are the most important inbound tourist source country of Fujian Province. preference trend of 3 countries is distinct, the United States raises first then falls, it is getting higher and higher from 2006, in 2010 it reaches to 4.21 highly, and then falls sharply. Malaysia's preference scale trend is contrary to the United States, rising first then falling, from 2.49 of 2006 down to 1.71 of 2009 , at last it rises fast and comes to 3.6 in 2015.

Singapore's preference scale trend is relatively stable, there is a small fluctuation between 2.15 to 3.03. Indonesia, Japan, Canada and Germany, the 4 countries have the weak preference market, the preference trend is relatively stable, there is fluctuation in the middle of range, which indicate that the inbound tourism market is relatively mature. The sparse scenery market includes Philippines, Britain, France, Australia and Thailand, which all belong to the weak sparse scenery market, the preference trend is relatively stable, and most of them are in low levels, especially Britain and France, their preference scale rises slightly, which shows that Fujian attracts tourists of Europe increasingly year by year, it should need to be focused on. Philippines and Thailand-the 2 Southeast Asian countries, in the early stage their preference scale value belongs to the weak preference tourist market, later they become weak sparse scenery, which shows that tourist attraction of Fujian Province, in the 2 countries are gradually decreasing,we need to strengthen the research.

\section{there is not a large difference between the preference countries, the trend of the countries is stable.}

It can be seen from Figure 1, in Fujian Province, the country has little difference about the inbound tourism market, the highest is 4.21 (2010) of America, the lowest is Thailand's 0.46 (2010), the difference of the two is less than 10 times. From the preference scale trend of countries, in addition to the United States and Malaysia with the high volatility, accounting for $83.3 \%$ of the other countries the trend is relatively stable with less volatility, indicating that these countries' tourists is relatively stable, we must adopt more targeted marketing way to attract more overseas tourists to visit Fujian.

\section{Conclusions}

The most important inbound tourist market in Fujian province is the United States, Singapore and Malaysia.

The country's relative trendof $83.3 \%$ is relatively stable with less volatility, indicating that the preference of tourists in these countries from Fujian have been relatively stable

\section{Policy recommendations}

\section{To take measures to consolidate the Southeast Asian market.}

From the geographical point, Southeast Asian countries are next to Fujian and with similar cultural background, there are many Chinese and Southeast Asian countries, the Chinese native of Fujian is in the majority, therefore, Southeast Asian countries have been the main source country of Fujian. To play the advantages of overseas Chinese, and to organize the Root Tour and Ancestor Worship Tour to attract more Chinese tourists.

\section{To excavate the European market in depth.}

In recent years, attraction for European tourists in Fujian is increasing year by year, we should focus on the development of the European market, with the tourism fairs held in the tourist country, fairs and other forms of publicity and promotion, we will improve the visibility of Fujian in Europe. According to the demand of European tourists to high-end tourism, Fujian should improve the level 
of tourism reception facilities to increase the yacht tourism, vacation and other high-end tourism projects [2], in order to meet the individual needs of European tourists.

\section{Reference}

[1] Ma Yaofeng, Liang Wangbing,Research on Tourism Market to China from America Based on Preference Scale, Travel Journal, Vol.20(2005), p. 35-38.

[2] Wang Chao, Ji Xiaomei,Study on the Evolution of The spatial and Temporal Structure of Inbound Tourist Market,Northwest Normal University (Natural Science Edition), Vol.52(2016), p. $119-123$ 